\title{
ENTRE CONVENÇÕES E DISCRETAS OUSADIAS: Georgina de Albuquerque e a pintura histórica feminina no Brasil*
}

\author{
Ana Paula Cavalcanti Simioni
}

O mundo artístico brasileiro esteve, durante grande parte do século XIX, pautado pela referência à Academia Imperial de Belas Artes e ao sistema de valores artísticos por ela propagados. ${ }^{1}$ Por muito tempo, a pintura histórica foi concebida como o mais importante gênero, impondo-se sobre aquelas faturas menores, como o retrato, a natureza-morta, a paisagem etc. Entre os artistas nacionais que se dedicaram ao gênero não há sequer um nome feminino até 1922, ano emblemático, ao menos segundo uma historiografia da arte modernista, da "crise" do academismo. ${ }^{2}$ Somente então, num período de contestação direta da legitimidade da Academia como instituição propagadora de valores para o campo das artes, é que

* O presente texto foi originalmente apresentado na XXV Anpocs, realizada em outubro de $2002 \mathrm{em} \mathrm{Ca-}$ xambu, na mesa redonda intitulada "Sociologia das Artes Plásticas no Brasil". uma mulher se realiza no gênero. Refiro-me à tela Sessão do Conselho de Estado (1922) (1) realizada por Georgina de Albuquerque.

A primeira observação dessa obra é surpreendente, pois ela contraria claramente determinadas expectativas que orientam a visão comum a respeito do que deve ser uma pintura histórica, sobre atributos específicos da autoria e sobre os motivos que melhor figuram um momento grandioso da história nacional. Georgina solucionou de forma singular a questão do tema, relativo à comemoração do centenário da Independência. Em vez de abordar um evento histórico triunfal, como uma cena de batalha, tal como o repertório acerca da pintura histórica nacional poderia the sugerir, apresentou um episódio diplomático dentro de um gabinete oficial. Ainda mais destoante é a figura heróica aí representada: uma mulher! Após uma leitura breve da legenda explicativa sabe-se, afinal, quem é a personagem central re- 
tratada, a Princesa Leopoldina, em meio a reunião de Conselho de Estado presidida por José Bonifácio, na qual se discutiu a necessidade de o Brasil tornar-se independente de Portugal, momento esse que teria antecedido o brado do Ipiranga. ${ }^{3}$

A ruptura com as expectativas ocorre porque, segundo E. Gombrich, ${ }^{4}$ o espectador, quando está diante de um quadro, opera com a sua capacidade de reconhecimento, isto é, mobiliza tanto seu conhecimento acerca dos objetos representados, quanto da maneira de representá-los e, para tanto, retira de sua memória toda uma tradição de telas anteriores àquela que se lhes apresenta, com as quais efetiva um diálogo, compondo uma tradição. Conforme o autor, nós espectadores

[...] esperamos receber uma certa notação, certos símbolos, e nos preparamos para entendê-los [...]. Os psicólogos chamam tais níveis de expectativa de "contextos mentais" [...]. Toda cultura e toda comunicação dependem da interação entre expectativa e observação, das ondas de gratificação, desapontamento, conjeturas acertadas e jogadas em falso, que constituem a nossa vida diária [...].

O quadro de Pedro Américo de Figueiredo e Melo, Independência ou Morte (1888) (2), tantas vezes exposto, reproduzido, citado e estudado que praticamente se tornou a "imagem oficial" do evento, não é o único modelo de figuração do marco da Independência, mas a referência mais óbvia da construção de Dom Pedro I como herói da nação que se constituía. Por meio desta tela criou-se o mito de uma proclamação da Independência como um evento bélico e conduzido por um benfeitor de armas em punho. Tal criação foi tão difundida que, em vez de vista como "invenção", foi tomada por "representação" de um fato.

A pintura de Georgina desafiava esse "contexto mental" ao se contrapor à de Américo em certos pontos, tais como: a) pela adoção de uma imagem de herói inovadora, uma vez que centrada em um personagem feminino (real e não alegórico, ${ }^{6}$ algo já mais recorrente); b) a sua composição, construída a partir de uma inversão do modus operandi tradicional, em que acima estão dispostos os figurantes, em vez de os protagonis- tas; c) pela feitura, diversa daquela "estética do acabado", nas palavras de Pierre Bourdieu, que bem definem o estilo acadêmico; e, finalmente, d) por um motivo extra-artístico: o autor da obra é uma mulher, uma pintora, e a tela é uma pintura de gênero histórico, ${ }^{7}$ geralmente produzida por mãos masculinas.

A quebra de expectativa com relação à tradição ocorre, assim, por motivos que são de ordem estética e, também, extra-artísticos. A associação entre a pintora e a heroína, numa semelhança por gêneros, é evidente demais para ser desprezada, embora seja, do ponto de vista absolutamente formal, algo "além" da arte, algo "do mundo", do social, e, por conseguinte, de fora, externo. Não se deve, todavia, compreender essa tela por meio de análises estilísticas que negligenciem o espaço social a partir do qual a autora a construiu. Esse lugar está delimitado por uma situação de gênero ${ }^{8}$ que, por sua vez, indica toda uma outra série de atributos, como a formação artística, um mercado específico, as estratégias diversas de afirmação pessoal e uma rede possivelmente diversa de sociabilidade. A maneira com que tudo isso se articula e toma forma numa tela é que o ponto instigante, e também por isso mais difícil, para uma análise. Seguindo a proposição de Antonio Candido, é preciso abandonar a dicotomia entre fatores externos e internos, uma vez que

[...] o elemento social se torna um dos muitos que interferem na economia do livro [e poderíamos dizer da tela], ao lado dos psicológicos, religiosos, lingüísticos e outros. Neste nível de análise, em que a estrutura constitui o ponto de referência, as divisões pouco importam, pois tudo se transforma, para o crítico, em fermento orgânico de que resultou a diversidade coesa do todo.?

Uma compreensão abrangente acerca dos significados gerais de Sessão do Conselho de Estado exige certos cuidados. O primeiro é o de circunscrever seu diálogo com outras obras, dentro de uma determinada tradição e, a partir daí, perceber os seus avanços e os seus recuos. Tal método derivado da história da arte mais contemporânea pode ser somado a outros, propostos pela his- 
tória da arte feminista e pela sociologia da cultura. É central a questão da formação artística recebida, não apenas porque aí se encontram os modelos que necessitam ser incorporados em construções posteriores como a questão mais propriamente sociológica: trata-se de uma artista mulher, formada em condições específicas, diversas das masculinas. Para tanto, é preciso recuperar, ainda que sumariamente, as condições de produção do trabalho artístico feminino no Brasil do século XIX. Esse ponto, por sua vez, nos leva aos modelos de realização da arte acadêmica e ao modo com que foram acessados, desigualmente, pelas mulheres.

\section{Alegorias da masculinidade: a tradição do herói masculino na pintura histórica}

Sabe-se que a implantação do sistema acadêmico $^{10}$ nos meios artísticos nacionais se deu com Missão Artística Francesa, em 1816. A Jean Baptiste Debret (1768-1848) foi entregue a cadeira de pintura histórica, dando início ao gênero no Brasil. O modelo dessa pintura seguiria os preceitos aprendidos com seu primo e mestre, o mais importante pintor francês do início dos oitocentos: Jacques Louis David.

Contrapondo-se a uma cultura que valorizava os elementos femininos, tal como o rococó, estilo dominante nas cortes dos setecentos, ${ }^{11}$ David construiu telas bastante marcadas pelo herói masculino e viril, onde a imagem se torna tão mais poderosa quanto maior o rigor na apresentação anatômica do corpo humano. O Juramento dos Horácios (1784) (3) é emblemático a esse respeito: observase o surgimento da força dos músculos tesos, tal qual espadas dos homens hercúleos, ao que a fragilidade das mulheres caídas do outro lado da tela funciona como oposto complementar. Se o herói é masculino e sua virilidade se expressa em seu corpo forte, a fragilidade é feminina e seu corpo é dormente, testemunho de sua desproteção.

A fraqueza feminina é novamente abordada em Os Lictores trazendo a Brutus os Corpos de seus Filhos (1789), adquirindo na obra características psicológicas do descontrole, de paixão, ao passo que o pai é o herói controlado e soberano de si e de seu temperamento. De maneiras diversas, os discípulos de David continuaram a investir nessa "simbólica dominação masculina". Nas composições do mestre as desigualdades apareciam de modo ainda contido em virtude de seu realismo, ${ }^{12}$ e também de sua participação ativa na implantação de um regime revolucionário e republicano que, a princípio, deveria incluir as mulheres. É preciso inclusive lembrar que os primeiros tempos da revolução concederam espaços às artistas e David foi um de seus mais importantes promotores. ${ }^{13}$

Com seus discípulos, a dominação sexual, antes insinuada, adquire uma evidência espantosa. Em Jupiter e Thetis (1811), Ingres faz uma analogia ao Império napoleônico através da imagem de um homem/divindade gigantesco que se impõe, com seu corpo descomunal, sobre a diminuta e sinuosa mulher, emblemática de uma relação de submissão. O recurso à analogia permite a Ingres aprofundar o exercício da dominação, de uma maneira que teria causado resistências à arte de David, sem qualquer tipo de medo da opinião pública. Recurso semelhante é usado por Delacroix, especificando-se que aí se encontra no imaginário orientalista - por si só um testemunho da dominação política - a solução para um aprofundamento da dominação masculina, que no caso de A Morte de Sardanapalus (1827) (4) beira um erotismo macabro. O mesmo pintor a estabelecer a imagem da revolução por meio da alegoria feminina foi capaz de concebê-la como objeto erótico, cuja vida e morte podem ser decididas em função dos desejos masculinos. Ambos usaram como recurso para que suas obras fossem bem aceitas pelo público o recurso do distanciamento alegórico, ora temporal, compondo as telas como se fossem de um passado mítico (até mesmo religioso), ora depositando no oriente inventado e sonhado as pulsões eróticas que não se aventuravam a reconhecerem em sua própria sociedade.

É verdade que o Brasil parece dissolver a intensidade das tradições. A obra de Debret no Brasil, segundo Rodrigo Naves, perde a intensidade da matriz francesa, seu vigor neoclássico se esvai e dissolve-se nas aquarelas, como resultado de uma sociabilidade avessa ao espírito revolucionário que alimentara a arte de David. ${ }^{14}$ Embora as 
causas apontadas pelo crítico sejam discutíveis, de fato a pintura histórica de Debret feita de acordo com as exigências da família real, não demonstra os contrastes entre masculino e feminino iniciados pelo mestre, aliás, parece mesmo adquirir um teor decorativo. Não apresenta também tamanho rigor na composição de seus heróis e ainda menos uma atenção tão especial ao corpo masculino. O mesmo já não se pode dizer de seu discípulo Manuel de Araújo Porto-Alegre, que, quando diretor da Academia (1854-1857), evidenciou a absorção dos padrões neoclássicos ao exigir dos pensionistas determinadas atitudes.

Se nas obras de Debret e mesmo nas de Porto-Alegre não está evidente o cânon davidiano com relação à composição histórica, isto não quer dizer que os valores, os modelos tivessem sido esquecidos. A importância do estudo do corpo humano, das aulas de nu, do conhecimento de anatomia e de sua transcrição fiel para as telas é bastante visível nas exigências que faz a Victor Meirelles, seu discípulo querido, no período em que ele está em Paris. Em carta, Porto-Alegre indica os passos que o jovem deveria seguir para compor a Degolação de São João Batista:

Antes de compor, veja a ação em geral, veja depois, cada uma das suas personagens: estude-as moral e fisiologicamente para que elas possam, cada uma de per si, compor um todo harmônico e verdadeiro. [E prossegue analisando o quadro enviado, que parece frustrar as expectativas de um corolário neoclássico, baseado na observação minuciosa do corpo humano.] A figura do algoz tem boa cabeça; o pescoço, o tórax e o abdômen estão sofrivelmente modelados e melhor coloridos, porque não tem tons sujos, porém, parece-me que há uma falhazinha miológica na região intercostal. O braço direito, no que toca o antebraço, não está mau, porém não está acentuado com energia, nem tem clareza na musculação: o deltóide deveria ser mais fibroso, assim como mais marcado o tríceps braquial; quanto ao antebraço, punho e mão, esses não foram estudados com tanto amor como o tórax e o abdômen. [...] As pernas parecem curtas, e um tanto inertes no modo de acentuar a musculação: o que está perfeitamente modelado é a parte externa da região poplítea e, sobretudo, a inserção posterior do tríceps da coxa. ${ }^{15}$
Tamanha exigência de conhecimento anatômico revela a importância do estudo de modelo vivo, tido como etapa fundamental para a composição da pintura histórica. ${ }^{16} \mathrm{O}$ produto final consistia numa obra que fora lentamente gerada. O aluno iniciava seu aprendizado no desenho, primeiramente de partes do corpo humano e, num estágio posterior, passava a aprimorar sua observação a partir dos bustos de gesso, com os quais se exercitava nos estudos de luz e volume. Cumprida essa etapa estava apto a subir um degrau e se tornar um estudante sênior, para tanto o ritual de batismo incluía o desenho a partir do modelo vivo, considerado o momento mais importante na sua instrução. ${ }^{17}$ Feito isso, poderia finalmente iniciar-se nos pincéis, primeiramente com uma cópia de algum detalhe de composição de algum grande mestre. A técnica ainda não visava a um ato construtivo, criativo, mas ao treino técnico. Essa etapa era denominada ébauche. A partir de 1816 foi introduzida uma inovação no sistema francês, qual seja, aulas de composição cujo resultado final seria a produção de esquisses por cada aluno. Esses seriam uma espécie de ensaio geral da tela concebida, em que a disposição da composição, cores e luminosidades já estariam presentes, mas com pinceladas soltas e sem uma preocupação com o acabamento. A última etapa seria o fini, a tela propriamente dita, em que se recupera o esquisse, mas controlando os efeitos de luz e conferindo-lhe acabamento, mediante o qual qualquer vestígio das mãos do pintor deveria ser retirado a fim de lhe conferir a impressão de perfeição almejada.

A Académie, ou desenho a partir de um modelo vivo, era a etapa que separava o rapin (estudante inicial) do estudante avançado, sendo, portanto, etapa primordial da formação de artistas e tendo um significado simbólico na carreira. Para tanto, contribuiu a própria hierarquia dos gêneros acadêmicos, em que pintura histórica reinava no patamar mais elevado. Esta se assenta numa tradição em que os grandes feitos eram, recorrentemente, simbolizados por um herói cujo corpo era modelado por músculos pulsantes, testemunhando de seu vigor e força, qualidades vistas como masculinas. O desconhecimento do corpo humano obstaculizava a carreira de um pintor 
que se pretendesse seguidor dos ditames neoclássicos. ${ }^{18}$ Foi justamente nesse ponto que o sistema acadêmico operou a exclusão das mulheres de seu universo. Mesmo que depois tenham sido criadas expressões, como a de "uma arte feminina", para se rotular e segregar os trabalhos das mulheres, uma vez que a expressão era aplicada, genericamente, às artes menores, como a pintura sobre porcelana ou tapeçaria. O que as excluiu não foi a ausência, natural, de capacidade estética, mas um preconceito cujas bases são sociais e que lhes interditou o acesso ao estudo do nu. ${ }^{19}$

O século XIX, no Brasil, gerou um número importante de pintores históricos. Nenhuma mulher faz parte da galeria. Os dois mais reputados artistas desse período foram Victor Meirelles e Pedro Américo. Para além da diversidade com que concebiam a pintura acadêmica, tão bem assinalada pelo crítico do período Gonzaga-Duque, ${ }^{20}$ ambos foram alunos da Imperial Academia, tendo a oportunidade de se formarem no cânon e conhecerem as obras dos grandes mestres em Paris. O Museu Nacional de Belas Artes possui vários estudos de modelos vivos feitos por eles, o que mostra que eram, cada um à sua maneira, exímios desenhistas. Se a educação artística não determina um estilo comum, ao menos abre as portas para que sigam carreiras paralelas.

Com isso volta-se a um ponto levantado no início deste texto: há questões aparentemente exteriores ao mundo da estética que são fundamentais para que se compreenda a gênese dos valores estéticos e a exclusão que eles operam. A questão da participação das mulheres no mundo da pintura acadêmica permite que esse sistema, auto-intitulado imune às pressões externas (concebendo a diferença entre os artistas como assentada em dons, por exemplo), se revele eivado de constrangimentos e relações de poder. A diferença entre homens e mulheres no que se refere à formação artística imputa espaços distintos, para uns e outros, nesse universo.

\section{A educação artística das mulheres no Brasil}

O tema da formação das artistas acadêmicas no exterior já está relativamente bem documenta- do pela bibliografia internacional. Embora a comparação seja inevitável e necessária, não cabe no espaço circunscrito de um artigo. Assim, este texto se limita a tratar apenas da questão da formação das artistas nacionais. No Brasil, a lei que permitiu o ingresso das mulheres nos cursos superiores foi promulgada em 1879, vigorando a partir do último decênio dos tempos imperiais. Até então estava formalmente interditada qualquer possibilidade acerca de uma completa profissionalização feminina, excluindo-se o professorado, que não exigia mais do que a Escola Normal. Tal permissão incluía o acesso à Imperial Academia de Belas Artes, mas parece não ter sido imediatamente seguida.

Vários motivos podem ser apontados para esse aparente descaso feminino em relação à oportunidade que se lhes abria. A ausência de uma tradição feminista de combate por direitos sociais, como a das norte-americanas ou ainda francesas, é uma das causas. Diferente da França, onde as mulheres já haviam se organizado como um grupo de reivindicação desde meados do XIX e exigiam sua entrada na École de Beaux-Arts, ${ }^{21}$ no Brasil, a lei fora promulgada a partir das reivindicações de um grupo restrito de mulheres (escritoras no geral), ${ }^{22}$ cuja preocupação estava centrada nas instituições de ensino profissionalizante tradicionais, como as faculdades de direito ou de medicina. Outro obstáculo diz respeito à dificuldade de serem aprovadas nos exames de admissão, uma vez que eram raras as escolas secundárias que aceitavam mulheres em suas fileiras. ${ }^{23} \mathrm{~A}$ consulta aos catálogos das Exposições Gerais de Belas Artes (após 1889, chamados Salões) revela que a lei demorou a se traduzir num ingresso efetivo de mulheres na escola. Elas, por algum tempo, continuaram sua formação tradicional: em ateliês particulares de professores vinculados à academia ou na Académie Julian, em Paris. Talvez a vergonha, uma sanção mais sutil, mas nem por isso menos eficaz, possa ter sido outro motivo. Afinal, uma mulher que pretendesse uma formação acadêmica estaria cometendo alguns desvios: um deles seria pleitear uma carreira pública, o que contrariava o espaço que lhe era sugerido pelos valores sociais, e o outro seria se postar (o que exigia muita coragem) diante de um modelo, vivo e nu diante de seus olhos. 
As primeiras matriculadas nas aulas de modelo vivo foram as escultoras Julieta de França e Nicolina Vaz de Assis, em 1898. Até então moças e senhoras insistentemente cursavam uma matéria, a mais elementar: desenho de ornatos. Poucas ousavam um passo adiante, como inscrever-se nos ateliês de pintura e escultura. Entre aquelas que visavam a uma formação mais sólida havia uma escolha comum: a ida para Paris, a fim de estudar numa escola que, reconhecidamente, teve o mérito de garantir às mulheres de elite de todo o mundo $\mathrm{O}$ acesso ao mesmo tipo de ensinamento acadêmico desfrutado pelos homens: a Académie Julian.

Entre as brasileiras que se formaram sob a orientação de Rudolph Julian, ${ }^{24}$ está justamente Georgina Moura Andrade de Albuquerque, nascida em 1885 na cidade de Taubaté. Seus primeiros estudos de pintura se deram com um professor particular, o sr. Rosalbino Santoro. Foi como sua aluna que expôs em 1903 na X Exposição Geral de Belas Artes, ainda com o nome de solteira. No ano seguinte ingressou na Escola Nacional de Belas Artes, onde conheceu o seu futuro marido, Lucílio de Albuquerque, também aluno da instituição. Em 1905 participou da XII Exposição Geral sem declarar ser aluna da instituição, apenas fazendo notar o nome de seu mestre, Henrique Bernardelli. Em 1906, parte para a Europa já casada com Lucílio, que recebera o prêmio de viagem ao exterior. Sua estadia em Paris trouxe-lhe uma ampla formação em técnicas diversas, adquiridas nas aulas de Paul Gervais e Decheneau, com os quais se informou sobre as artes aplicadas. Institucionalmente participou dos dois grandes centros de formação, a École de Beaux-Arts, fato que fará constar em todas as exposições de que participou e, ainda na Académie Julian, uma instituição fundada em 1868 e que tradicionalmente recebia brasileiros. ${ }^{25}$ Aí teve como professor Henry Royer. O aprendizado na escola seguia critérios acadêmicos comuns à École de Beaux Arts, tendo inclusive em seus quadros professores da tradicional instituição, tais como Cabanel, Bouguereau entre outros.

Julian percebera que havia um interesse importante da clientela feminina internacional em uma educação artística nos moldes da masculina, em última instância, percebeu que a profissionalização feminina seria um bom negócio.
Apesar de o curso ser caro e as classes de homens separadas das de mulheres, ainda assim lhes fornecia o mesmo tipo de treinamento. A chave da formação era o desenho, que exigia destreza, trabalho e paciência; ao que se seguiam as cópias de grandes mestres. Além disso, estimulava uma competitividade interna, por meio de prêmios, criando um ambiente mais próximo ao da École, preparando suas alunas, inclusive psicologicamente, para as duras exposições que deveriam enfrentar. O seu diferencial, todavia, foi o estabelecimento de classes de estudo do modelo vivo para mulheres, que se saiba o primeiro curso a ser-lhes oferecido mundialmente.

Muitas mulheres estrangeiras aportavam em Paris procurando acessar as instruções que lhes eram vetadas em seus países, entre elas a russa Marie Bahkirtseff, que representou bem as aulas com modelos em sua tela In the Studio (1881) (5). O jovem modelo posa, com seu tapa sexo, para moças ávidas por capturarem com o melhor ângulo possível a anatomia de seu corpo. Há vários nus femininos elaborados por elas que provam que Julian não apenas estimulava o gênero, como também tornava mais sofisticado o ponto de vista do observador, por meio de poses pouco convencionais. A solução era clara: as modelos seriam preferencialmente mulheres, no caso de homens posariam com um pano em suas partes "perigosas". Isso garantia a boa formação das mulheres, sua inclusão nos estágios da formação de artistas, sem provocar a ira de seus pais, ou da "boa" sociedade. Os estudos de Académie tinham ainda uma segunda importância para as mulheres: viabilizavam suas carreiras como retratistas, mercado que lhes era mais promissor. ${ }^{26}$

A passagem de Georgina pela escola garantiu-lhe uma série de aprendizados, entre eles o aprimoramento na representação do modelo vivo. Além disso, a instituição incitava os debates sobre arte feita por mulheres, e até mesmo uma competitividade interna entre elas, ocasionando uma certa consciência sobre a situação das mulheres artistas. Do ponto de vista formal, a educação recebida permitia-lhes que se dedicassem a gêneros diversos, ainda que o retrato fosse o mais rentável, também havia a possibilidade de se dedicarem à pintura de gênero histórico. E por que não 
o faziam? Desde o século XIX algumas pintoras brasileiras passaram por lá, sendo a primeira Berthe Worms, importante retratista em São Paulo. Mas somente em 1922, com o trabalho de Georgina, vemos uma mulher se dedicando ao gênero que fora tido, no passado, como o mais elevado dentro da hierarquia acadêmica.

Novamente, é impossível pensarmos em uma única causa. Em primeiro lugar, deve-se lembrar que, quando as mulheres ingressam em massa nas academias - isso no plano mundial se dá em finais do XIX -, é justamente o momento em que tais instituições estão em plena crise. A saturação do sistema que lhes servia de base gerou seus próprios críticos, ${ }^{27}$ como os impressionistas, que estruturaram um sistema artístico paralelo e independente do oficial, indicando a agonia daquele esquema centralizador. A grande pintura histórica já carecia de encomendas e também de público nos maiores centros e, desde os anos de 1830, na França, presenciava o declínio de sua magnitude em relação à pintura de gênero. A III República fomentou um revival por meio de encomendas públicas que visavam a "educar as massas" segundo a moral do Estado, de sorte a valorizar temas determinados e um estilo classicizante. Porém, isso ocorria concomitantemente à perda de centralidade do Salon e da própria Académie diante de um sistema artístico complexo, inclusive pelo fortalecimento de um mercado artístico paralelo e não subordinável ao gosto oficial. No Brasil, houve um certo mecenato durante a I República sobretudo por parte do Museu Paulista, em São Paulo, mas este não era comparável às encomendas públicas ensejadas pela Guerra do Paraguai, as quais engendraram as obras de Pedro Américo e de Vitor Meirelles que tornaram célebre a exposição de 1879 .

As encomendas advindas de São Paulo incluíam poucas mulheres, e quando o faziam a escolha se pautava pelas paisagistas, e não pelas retratistas. ${ }^{28}$ Ainda assim é possível que a comemoração do Centenário da Independência, juntamente com a política de Taunay, levada a cabo no Museu Paulista, de constituição de uma "memória paulista” por intermédio de realizações iconográficas, tenham estimulado um revival, mobilizando os artistas a adequarem o gênero aos ditames da "moda" e do tempo. ${ }^{29}$
Ainda que com a República as mulheres tenham passado a expor em maior número seus trabalhos nos salões, as telas de grandes dimensões mantinham-se como tabus. Os motivos são dificilmente recuperáveis dada a ausência de documentação, e entramos, assim, na ordem dos prováveis. Uma tela histórica é feita em grandes dimensões e para ser exposta em logradouros públicos, para freqüentadores desconhecidos, anônimos. Tratase de um gênero que não está destinado à esfera doméstica. E também não se trata de uma produção que possa ser vista como resultado de um aprimoramento nas "prendas do lar". Difere radicalmente do retrato privado e também das naturezas-mortas, gêneros afeitos aos ornamentos dos lares burgueses. Uma mulher que ousasse pintar um quadro histórico estaria rompendo com a equação, já mais do que conhecida, de que a ela caberia o espaço da casa, enquanto ao seu marido e aos seus filhos homens estava destinado o espaço da rua, do trabalho, em suma, da vida pública. Desafiar esta ordem das coisas poderia trazer dissabores. E isso ocorria não apenas no Brasil, mas também na França:

[...] as mulheres ainda tinham de combater a visão predominante (codificada nas exclusões institucionais e nos discursos da crítica, da ciência, da medicina, do direito e da moralidade) de que um engajamento sério e profissional com a arte estava além das capacidades de uma verdadeira mulher. Se houvesse mulheres que demonstrassem uma capacidade artística excepcional, então o sentimento era que elas tinham necessariamente de renunciar a seus atributos intrinsecamente "femininos", e assim ameaçavam solapar toda a estrutura social sobre a qual se erguia a França moderna. Se as mulheres fossem abençoadas com uma sensibilidade refinada e uma percepção estética desenvolvida, isto deveria ser expressado nas atividades adequadas dos afazeres domésticos, o bordado, a montagem de álbuns e a pintura de aquarelas, nada muito difícil ou ambicioso, nada que as afastasse de seus deveres primários de esposas e mães. Ser uma artista profissional era, em muitos lugares, transgredir as expectativas sociais [.....$^{30}$

Uma coisa era ser uma mulher educada, que soubesse receber bem, entabular boas conversas, fazer-se agradável ao piano, e cujas mãos servis- 
sem para decorar e tornar o lar um espaço aconchegante. Essa era a mulher desejável dentro dos padrões vigentes. Se o pendor artístico respeitasse os limites da casa, era um dom legítimo, mas se tornava impertinente quando associado a um desejo de afirmar-se em público. A pintura era uma prenda e não uma carreira. As artimanhas pelas quais as mulheres eram desencorajadas a se tornar artistas profissionais exigem uma pesquisa bastante minuciosa do discurso dos críticos, da imprensa, das caricaturas de época, e também das premiações acadêmicas. Embora não se possa ainda tecer afirmações contundentes a esse respeito, o próprio testemunho de Georgina Albuquerque insinua algumas pistas sobre o tipo de desafio que as mulheres encontravam.

Há pouco, mesmo, o senhor me falou de um quadro meu de que disse gostar muito, e que, geralmente agradou. É aquela menina repousando sob a sombrinha encarnada...

Pois sabe o que aconteceu a esse quadro?

Pintei-o pensando pleitear uma medalha, um prêmio qualquer, de estímulo no salon. Mandei-o à exposição. O quadro agradou, todos me disseram isto, inclusive membros do júri, mas não obteve a medalha. Apenas, como ficha de consolação, deram-me 500\$, mandando o júri igual quantia, para outra pintora, muito talentosa, que concorrera à mesma recompensa que eu.

A minha colega, mais sonhadora e impressionável, talvez, sofreu um golpe, tão rude, que abandonou o pincel, não quis mais se dedicar à arte, deixou a profissão onde começara tão bem. Eu não. Melhor formada para essas decepções, guardei os $500 \$$ e continuei a trabalhar, com perseverança e destemor. ${ }^{31}$

Premiações injustas agregadas a prêmios de consolação, críticas adocicadas às obras, estados de gravidez que interrompiam as carreiras e exigiam uma dedicação total ao lar, vários eram os desafios dessas mulheres. Georgina relata o episódio de sua amiga que, menos teimosa e determinada que ela, diante do primeiro caso de negação de seu talento, desistiu de sua trajetória artística. É de se imaginar a que tipo de comentários e pressões estaria sujeita uma mulher que ousasse pin- tar uma tela de gênero histórico, centrada na figura de um herói cujo corpo bem delineado a todos mostrasse que estivera sentada, horas, diante de um modelo nu; e cuja pretensão era competir, diretamente, no campo em que os artistas homens haviam pleiteado a aclamação pública de suas qualidades geniais. Essa mulher, no mínimo, frustraria as crenças de que a submissão e o recato eram as qualidades de seu sexo.

É provável que esse temor fosse comum a várias mulheres dessa geração. Uma coisa era pintar, expor, outra era considerar essa atividade um trabalho que as expusesse para além do espaço destinado à mulher: o doméstico. Em atitude oposta, Georgina, em 1922, exibiu uma tela em que reivindicava o posto antes reservado apenas aos homens: o de pintora de gênero histórico. Sua ousadia estava ancorada em uma carreira artística de prestígio: em 1907, recebera sua primeira menção honrosa, em 1912 e 1914, obtivera medalhas de prata nos Salões nacionais e, em 1919, obteve a premiação máxima: a medalha de ouro com a tela Familia. Tal feito ensejou oportunidades institucionais. Em 1920, tornou-se a primeira mulher na história da arte brasileira a participar de um júri acadêmico. Sob tais bases sólidas deflagrou a atitude pouco convencional de pretender firmar-se como pintora de história. E não é improvável que almejasse figurar nas salas de algum museu, sendo agraciada com uma encomenda pública e com a perpetuação de seu nome na galeria dos ilustres pintores responsáveis pela criação de uma memória para a nação. Após essa digressão é hora de retornar à tela Sessão do Conselho de Estado, pois é na sua feitura que as ambigüidades e ousadias de uma pintura elaborada por uma mulher tomam corpo.

\section{A ousadia contida de Georgina}

Qualquer tentativa de compreender os reais intuitos que guiaram as mãos de Georgina na constituição da tela tem algo de especulação. A única documentação com que se pode contar é a própria obra, testemunho por si mesmo polissêmi$\mathrm{co}$, que nos permite apenas interpretações incertas. A análise ganha solo mais firme quando pau- 
tada pela relação a uma determinada tradição de pintura, a qual, neste caso, excluiu a mulher tanto da atividade criadora quanto de uma primazia visual, posto que o heroísmo esteve associado às qualidades masculinas. Ao que parece, Georgina tentou afirmar-se, em sua tela, como uma mulher pintora de tema histórico, por meio da figuração de um novo tipo de herói. Se a iniciativa é ousada, a fatura indica um viés de conservadorismo ou de compromisso com linguagens que poderiam ser tomadas, se referendadas por parâmetros rígidos, como excludentes.

Georgina firmara sua reputação como artista impressionista, estilo que, na França, provocou a crise do sistema acadêmico ao propor como solução final das telas o ébauche e não mais o fini, desafiando a própria noção de arte tradicional. ${ }^{32}$ Escreve Bourdieu que a arte acadêmica se caracteriza pelo controle estatal, que exige dos pretendentes, ao deter o monopólio das chances de carreiras, essa arte da destreza técnica, essa pintura que não se afirma autônoma, mas, ao contrário, se pretende "legível" em vez de "visível":

Com efeito, a virtuosidade técnica que é, com a exibição de cultura, a única manifestação admitida da maestria, só pode realizar-se negando-se: o acabado é o que faz desaparecer todo o vestígio do trabalho, da manufatura (como a pincelada que, segundo Ingres, não deve ser visível, ou o toque, "qualquer que seja a maneira como é dirigido ou empregado, é sempre um sinal de inferioridade em pintura", como escreve Delécluze em Les Débats), ou mesmo da matéria pictórica (é conhecido o privilégio conferido à linha em relação à cor que se torna suspeita pela sua sedução quase carnal), em suma, de todas as manifestações da especificidade do ofício é ele que faz com que, no termo desta espécie de realização autodestrutiva, a pintura seja uma obra letrada como as outras, passível da mesma decifração que a de uma poesia. ${ }^{33}$

Manet negara tudo o que dizia respeito à técnica tradicional na segunda metade dos oitocentos. Recusara a supremacia do fini, subvertera a escala dos temas e passara a cultuar o que antes era visto como assunto indigno para a arte sublime: as cenas cotidianas, as cortesãs, as cenas de bares, a natureza vista de fora do ateliê. Do ponto de vista da feitura, ele contestava a noção de que "o esboço se distinguia do quadro como a impressão que convém à fase primeira, privada, do trabalho artístico, distingue-se da invenção, trabalho de reflexão e de inteligência feito na obediência às regras e apoiado na busca erudita, sobretudo histórica". ${ }^{34}$ Como afirma Bourdieu, "Manet, ao impor à sua obra uma construção cuja intenção não é a de ajudar à 'leitura' de um sentido, condena a uma segunda decepção, sem dúvida mais fundamental, um olhar acadêmico acostumado a perceber a pintura como uma narrativa, uma representação dramática de uma 'história'”. ${ }^{35}$

Quando Georgina adere ao impressionismo, já em inícios do século XX, o estilo havia se "academizado". O II Império francês caracterizou-se, ao longo dos anos de 1850 até 1870, pela difusão de uma solução pictórica que estava a meio termo tanto das linguagens produzidas pelas vanguardas, como a de Courbet, quanto de uma estética defendida por acadêmicos tradicionalistas, dando ensejo a produções de compromisso, denominadas juste milieu. A III República manteve a tendência às soluções intermediárias, ora levando a um naturalismo classicizante ora a uma incorporação acadêmica do impressionismo. As obras de Cabanel, Bouguereau, professores de vários artistas brasileiros que estagiaram no exterior, incluindo aqueles que passaram pela Académie Julian, combinavam a luz e a cor modernistas (absorvidas do romantismo e do impressionismo) com a centralidade do desenho e das temáticas conhecidas e apreciadas por um público burguês. ${ }^{36}$ Conforme aponta Alexandre Eulálio, eram justamente essas obras que contavam com algum mercado consumidor no Brasil:

Já então o colecionismo começava a se definir segundo um paladar eclético, estimulando (era inevitável) pelos costumes mundanos da Paris III República. Multiplicam-se então as viagens à Europa [...]. A pintura que pode interessar a esse público terá de ser naturalmente aquela acessível ao filisteísmo mundano e novo rico, não a grande pintura, sempre difícil e sem concessões - nem aquela do passado, nem, muito menos, a experimentação vanguardista do tempo. ${ }^{37}$ 
Se utilizássemos os critérios vigentes até os anos de 1970 para classificarmos a obra de Georgina veríamos que sua tela jamais seria tomada pelos acadêmicos como uma pintura de boa qualidade. Suas afinidades estilísticas e temáticas com Mary Cassatt são tão evidentes que qualquer espectador a enquadraria nas mesmas fileiras da pintora impressionista norte-americana. Como ela, consagrara-se pintando cenas cotidianas de mulheres ao sol, nos parques, com seus filhos. Temas que cabiam bem a uma mulher, e também a uma pintora impressionista. Porém, no Brasil, Georgina sempre foi conhecida como pintora acadêmica. Contribuiu para tanto uma série de motivos associados à sua trajetória: ser esposa de um pintor reconhecido pela academia, ter exposto freqüentemente nos salões, ter seguido uma carreira vinculada à instituição, chegando mesmo a ocupar o posto de diretora, após ter sido professora da casa.

A tela Sessão do Conselho de Estado é indicativa desse movimento de academização do impressionismo e, em contrapartida, de inovação da pintura acadêmica. O colorido intenso dominado pelos tons em laranja e amarelo, que aparecem em outros trabalhos seus, proporcionam grande vibração ao quadro, mais do que seria adequado a uma pintura bem feita nos moldes neoclássicos vigentes ao longo do século XIX. As pinceladas fortes foram mantidas, de modo que qualquer preocupação com a perfeição do acabamento, em que uma ilusão de realidade pudesse se manifestar, está aí ausente. Tanto nas cores, quanto no tipo de pincelada, a tela é evidentemente impressionista. Mas tanto a temática, o enquadramento, quanto a grande dimensão e a clara preocupação com a fidedignidade aos rostos dos retratados, assemelham-na a uma pintura de gênero histórico convencional. Isso a afasta dos impressionistas, na medida em que uma das bandeiras contra a academia era a subversão dos temas ditos consagrados para a arte; a profanação que procederam contra a arte tradicional foi a de se contraporem à sua narratividade, sobretudo histórica. Assim Georgina nos apresenta uma estranha combinação: um estilo aparentemente impressionista numa tela que se pretendia, segundo as classificações costumeiras do sistema acadêmico, ser um gênero mais conservador.
Do ponto de vista formal, o mínimo que se pode dizer é que Georgina foi tímida, pois buscava essa solução de compromisso já repetidamente utilizada por artistas franceses os quais conheceu, ou como aluna ou como espectadora, em seu período de formação na França. Tais fórmulas, presentes ainda nos anos de 1980 em artistas denominados juste milieu foram absorvidas por vários outros artistas brasileiros como Visconti, Calixto, Amoedo, Décio Villares, Manoel Lopes Rodrigues, Firmino Monteiro, entre outros, constituindo-se como um patamar de atuação seguro, com um público relativamente estável, ou, em outras palavras, demonstrava um desejo de atualização, um gosto pelo moderno, mas sem grandes ânsias pela ruptura com o sistema acadêmico.

Porém, é esse tipo de composição pouco ousado formalmente que garante sua inovação, se pensada à luz da tradição da pintura histórica brasileira e seu significado para as mulheres artistas. Primeiramente por afirmar-se publicamente como uma mulher pintora que escolheu o desafio de enfrentar a temática histórica. Afinal expunha-se ao julgamento público (e esse termo amedrontava suas colegas) sua capacidade de pintar uma tela com grandes dimensões, onde estava em jogo a competência na representação do corpo humano. A passagem pela Académie Julian mostra-se aí frutífera, são muito bem feitos os retratos, notando-se a ênfase nos rostos. Mais engenhosa e curiosa é a escolha do tema: atribuir relevância histórica à princesa Leopoldina no que diz respeito à Independência do Brasil.

A realização de Georgina não pode, portanto, ser compreendida apenas a partir de um ponto de vista estético. Se os olhos forem os do crítico de arte, se verá em sua obra apenas o que possuem de mais frágil: a absorção estilística de uma fatura associada a um gosto burguês, como é o juste millieu. Mas se for recolocada dentro de uma determinada tradição artística de um modo mais amplo, englobando os valores sociais e políticos que são reproduzidos pelo sistema de ensino artístico, o qual distribui desigualmente as chances de carreira para os indivíduos, torna-se perceptível a discreta ousadia de sua proposta. No mínimo subverteu a imagem de herói correntemente 
aceita e mais, ampliou as linhas que demarcavam o espaço de atuação das artistas mulheres. Como postulam as historiadoras da arte feministas, a invenção de um olhar puro é um exercício da dominação masculina. Quem quiser trabalhar com arte feita por mulheres não pode aceitar o cânon e julgar suas obras a partir de um padrão que as excluiu, por séculos, de todo o sistema de produção e consagração das obras. ${ }^{38}$

A tradição de nossa pintura, que conforma nosso imaginário, depositou em homens, principalmente nos regentes, os feitos grandiosos de nossa história. As mulheres, com exceção das princesas Isabel e Leopoldina, permaneceram como acompanhantes, nos bastidores. Na tela, Georgina centrou a cena na princesa Leopoldina, indicando o seu papel de articuladora política, visto como fundamental para o evento celebrado. O modo com que o faz também deve ser destacado: ela não está ao centro, com uma espada, e tendo abaixo os homens (ou o povo, se se quiser), tal qual aparecia nas pinturas alegóricas ou naquelas em que o herói era um homem. Essa heroína é serena (contrariando a noção da mulher como um ser sem controle sobre suas paixões); não se coloca acima dos homens (mas eles lhe rendem homenagem, ainda que estejam mais altos); não faz a guerra, mas a articula; não dá "o grito", mas o engendra, sua força é intelectual.

Vale a pena lembrar que esse "golpe" de Georgina fora tomado poucos anos depois de receber a medalha de ouro na Exposição Geral de Belas-Artes de 1919 e, graças a isso, ter-se tornado a primeira artista mulher a participar de um júri (de pintura, no caso), no ano seguinte. Seu gesto singular tinha sólidas bases institucionais, como a posição na academia, a carreira bem-sucedida, o matrimônio com um também condecorado pintor etc. Georgina soube como poucas artistas manipular a seu favor os mitos em torno de um casamento feliz, em uma época de valorização da mulher culta como boa mãe republicana. Sua tela é também uma projeção dos ideais em torno da desejada mulher republicana: feminina, culta, forte, mas jamais "competitiva". A princesa Leopoldina é uma de suas melhores expressões, ainda que associada a um passado Imperial. Também Georgi- na representava esse protótipo desejado de uma mulher que soubera harmonizar os interesses de realização profissional com as exigências e as satisfações de uma vida familiar feliz. Como Angione Costa afirma, o casal foi responsável, conjuntamente, pela criação de uma grande obra: a vida perfeita.

A casa de D. Georgina e de Lucilio de Albuquerque é um sereno recanto onde se vive da arte e para a arte. Aquele casal realiza bem o ideal de perfeição, dificilmente atingido, e vai dando à vida a mais graciosa impressão de encanto, possível num lar de artistas [...]. São o que se pode desejar um casal acertado, duas criaturas que se uniram para a realização de uma grande obra e vão dando ao seu sonho a elasticidade concreta de uma vida perfeita [...]. ${ }^{39}$

Georgina foi capaz de combinar trunfos diversos como os de uma sólida formação artística; uma determinação incomum que se evidencia na persistência com que expunha nos salões; ${ }^{40}$ a imagem de mulher competente nos moldes republicanos, o que incluía uma formação intelectual e mesmo profissional que não obliterasse as atividades de mãe e esposa, às quais se dedicou infatigavelmente e, finalmente, o apoio do marido, também pintor, Lucílio de Albuquerque, cujo companheirismo proporcionou-lhe o conforto interno necessário para que ousasse ultrapassar as barreiras erguidas para as mulheres de sua geração. Sua auto-afirmação como pintora de temática histórica se deu no ano em que o sistema acadêmico sofreu as mais demolidoras críticas. É curioso notar que, pouco antes de Anita Malfatti e de Tarsila do Amaral se consagrarem como artistas exemplares do modernismo, justamente o estilo que se insurgia contra o academismo, era uma outra mulher que, navegando por outras correntes estéticas, afirmava-se, publicamente, como artista e profissional.

\section{NOTAS}

1 Sabe-se que o impacto da instituição, entretanto, é desigualmente importante ao longo do vasto território 
nacional. Em alguns lugares, como Salvador, os sistemas locais continuaram fortes e resistiram aos novos modelos que chegaram da França, com a Missão Artística de 1816.

2 Refiro-me ao impacto da Semana de Arte Moderna e sua demolição, ao menos no plano dos valores e das idéias, do estilo e da importância da Academia.

3 Diz a legenda da tela "Convocou-se ao Conselho de Estado para o dia primeiro de setembro (ou 2), às 10 hs da manhã. Já estavam todos os ministros presentes no Paço. Fez José Bonifácio a exposição verbal do estado em que se achavam os negocios publicos, e concluiu dizendo que não era mais possivel permanecer naquella dubiedade e indicisão, e que para salvar o Brasil cumpria que se proclamasse immediatamente a sua separação de Portugal. Propoz então que se escrevesse a D. Pedro que sem perda de tempo puzesse termo alli mesmo em São Paulo a uma situação tão dolorosa para os brasileiros. Todos os ministros applaudiram o alvitre e com elles emulou no enthusiasmo a Princeza Real." (Rocha Pombo, 1905, p. 743). Percebe-se que a pintora escolhe como marco para a Independência o momento de seu engendramento, no qual a princesa toma papel ativo, e não o de sua realização simbólica levada a cabo pelo governante. Ao que parece, o regente foi um mero executor das decisões tomadas em sua ausência, pelos "intelectuais" de Estado, dentre os quais a sua própria consorte.

4 Refiro-me, em especial, aos estudos desenvolvidos por ele em Arte e ilusão: um estudo da psicologia da representação pictórica, 1986 e La Imagen y el Ojo, 1993.

5 Ver E. Gombrich, 1988, pp. 51-52. Neste livro o autor mostra o quanto a "memória artística" ou schematta, ou seja, a série de convenções sobre a representação, é que guia a própria possibilidade de representar, construindo o olhar. Não existe, portanto, um olhar puro que capta a realidade, mas sim um modo de apreensão conformado numa determinada tradição, que percebe, no real, aquilo que merece ser fixado, op. cit., pp. 77-78.

6 A mulher foi tratada como alegoria da República ou da Nação diversas vezes no Brasil. Estou consciente da importância do tema mas infelizmente não pude aprofundá-lo neste texto, pois demandaria uma pesquisa iconográfica que ainda está em andamento e leituras apropriadas. Sobre a utilização das alegorias femininas na pintura brasileira vale a pena ler José Murilo de Carvalho, 1990

7 Segundo o Grand dictionnaire universel du XIXe siècle, "l'expression peinture de genre a été imagi- née par la critique moderne, pour designer les compositions dont les sujets sont empruntes à la réalité et copiés, pour ainsi dire, sur le vig, par opposition à celles qui expriment, d'une façon idéale, des scènes historiques, religieuses ou de pure fantasie, et qui constituent la 'peinture d'histoire'". Todavia, ao longo do século XIX, as oposições entre os gêneros foram se atenuando, sobretudo por meio da adoção de soluções intermediárias por parte dos artistas, combinando temas históricos com cenas cotidianas, ou mesmo as características formais mais arrojadas do realismo (e também do impressionismo) com assuntos elevados. A pintura de gênero histórico pode ser vista como uma dessas soluções de compromisso ao combinar temas tradicionalmente considerados elevados, com uma fatura mais modernizante.

8 Nos últimos decênios, os debates sobre gênero foram incorporados à história social da arte, trazendo abordagens renovadoras para a disciplina. Em especial consultar Griselda Pollock, 1994; e Linda Nochlin, 1994.

9 Antonio Candido de Mello e Souza, 2000, p. 8, grifos meus.

10 Por sistema acadêmico entende-se o conjunto das instituições envolvidas com o ensinamento e práticas acadêmicas: Imperial Academia de Belas-Artes e as Exposições Gerais de Belas Artes (mais tarde, com a República, denominados Escola Nacional de Belas Artes e Salões Nacionais de Belas Artes, respectivamente). Seria interessante também levar em consideração os ateliês particulares de professores vinculados à Imperial Academia na medida em que ampliavam o círculo de aspirantes à profissão, ainda que fornecendo um ensinamento menos "oficial", mas nem por isso avesso aos padrões vigentes.

11 A sociedade de corte francesa estava assentada em uma desigualdade de posições sociais baseadas no sangue e na tradição, porém, entre si os nobres eram vistos como iguais, incluindo homens e mulheres. As mulheres eram socialmente importantes ora como promotoras de salões, e assim, de círculos de sociabilidade centrais, ora como intelectuais ou artistas. Duas pintoras se destacaram no período: Adélaide Labile-Guiard (1749-1803) e Elisabeth Vigée-Lebrun (1755-1842), ambas retratistas bastante solicitadas pela corte e sobretudo pela Rainha. Quando se pensa em um "estilo feminino" está se pensando em pintores como Boucher, entre outros, e os retratos de corte em que os modelos estavam bastante marcados pela pompa, ritual e trejeitos revelando sua posição aristocrática. David, em contraposição a isso, "limpa" as figuras heróicas de seus trabalhos 
de qualquer tipo de exagero na indumentária, ou da expressão, que possa lembrar vestígios dessa sociedade teatral. Seus retratos acentuam a bravura dos feitos, das conquistas, do trabalho, reforçando uma masculinidade das atitudes dos modelos.

12 O estilo de David consistia, entre outros fatores, em apresentar cenas heróicas de um presente, ou melhor, de tornar presente o heroísmo. Uma das coisas que desejava era o reconbecimento por parte do público de que os eventos históricos tutelados por Napoleão Bonaparte, a quem sua pintura servia, eram grandiosos tal qual os do passado, sobretudo aquele que originara a civilização ocidental. A idéia de uma dominação de homens sobre mulheres está implícita em suas telas, mas não escancarada uma vez que, ao menos inicialmente, as mulheres deveriam participar da república instaurada. Mas tal dominação, com contornos eróticos bastante valorizados pelo público dos salões, é aceitável quando escondido por trás de uma roupagem alegórica. É freqüente, por exemplo, na pintura orientalista. E também será aceitável, no Brasil, quando se trata do corpo feminino da mulher indígena. Temos exemplos como: Moema, ou ainda, A Faceira, sem equecermos de Marabá. A esse respeito ver Bernardete Dias Cavalcanti, 1998.

13 Alguns trabalhos mencionam o papel de David como professor de pintoras mulheres, ressaltando que, logo após a Revolução, as mulheres conheceram grande abertura para participarem dos Salões. Ao longo do XIX, porém, viram esse espaço diminuir e acompanharam a criação de um espaço separado para as mulheres, que passaram a receber formações distintas. Ver Whitney Chadwick, 1986, e, em especial, Margaret Fields Denton, 1998.

14 Rodrigo Naves afirma que a tradição barroca do Brasil, aliada à uma sociabilidade em que a escravidão é um incômodo permanente e demasiadamente visível nas ruas, obrigaram Debret a "rebaixar" suas experimentações neoclássicas e tentar encontrar uma nova forma que lhe permitisse fixar as cenas cotidianas, o que o levou para as aquarelas. Um neoclassicismo assentado em uma concepção republicana e igualitária era inviável num país marcado pela desigualdade. Ver Rodrigo Naves, 1997.

15 Citado por Jorge Coli, s. d., pp. 35-36.

16 N. Pevsner analisa a centralidade que o estudo a partir do modelo ao vivo adquiriu na montagem do sistema acadêmico francês, ao longo do século XVII. Foi o seu monopólio por parte da academia que garantiu que prevalecesse sobre as antigas cor- porações. Quando se chega ao século XVIII, o sistema adquiriu grande complexidade, sendo muito mais do que uma organização de aprendizado, mas sim um ponto de cruzamento de formação artística, de criação estética, de adequação da oferta de obras para uma clientela específica, com princípios próprios de funcionamento. O século XIX conserva a organização tradicional da instituição até sua perda de prestígio na transição para o século XX. Ver Nicokolaus Pevsner, s.d.

17 Alber Boime, s. d., p. 30.

18 Vale ressaltar que, ao longo do século XIX, a pintura histórica foi perdendo importância em relação à pintura de gênero.

19 Esse é a causa da exclusão das mulheres do estudo do nu para as historiadoras da arte lidas até agora. O mesmo argumento é citado por Tamar Garb, Margaret Denton, Catherine Feher, Anthea Callen, Griselda Pollock.

20 Sobre as exposições artísticas e os pintores de finais do século XIX a mais importante obra conhecida é Arte Brasileira, publicada inicialmente em 1888, de autoria de Luis Gonzaga-Duque Estrada, o mais eminente crítico do período.

21 Há vários livros e artigos que discutem essa questão com mais profundidade, entre eles: Marina Sauer, 1990, e Tamar Garb, 1994, 1998 e 1999.

22 Algumas teses já chamaram a atenção para o fato de que as mulheres reivindicavam sim seu lugar na esfera pública, mas eram poucas, e no geral eram jornalistas e propagavam suas idéias através da imprensa feminista. A esse respeito ver Maria de Lourdes Eleutério, 1997.

23 Acerca da dificuldade da educação feminina no século XIX destaca-se, entre outros, Maria Theresa C. C. Bernardes, 1989.

24 Embora a pesquisa ainda esteja em andamento, já é possível afirmar que algumas artistas expressivas passaram pela escola de Julian, entre elas: Fédora do Rego Monteiro, Tarsila do Amaral, Bethe Worms, Georgina de Albuquerque, Helena Pereira da Silva Ohashi e Nair de Teffé.

25 Jorge Coli menciona vários pintores importantes do XIX que passaram por lá. Estranhamente, não menciona pintora alguma. São eles: Belmiro de Almeida, em 1884; Mário Barbosa, entre 1902 e 1903; Rodolfo Bernardelli, 1893; José Marques Campão, em 1910; Henrique Cavalleiro, em 1919, Roberto Colin, em 1905; Eliseu Visconti, entre 1893 e 1896 e Pedro Weingartner, 1882-1884. Ver Jorge Coli, s. d., p. 193. 
26 Sobre a formação das alunas na Académie Julian e a ênfase na formação de retratistas ver Gabriel Weisberg e Jane Becker (orgs.), 2000.

27 A esse respeito ver WHITE, H. White e C. White, 1993.

28 Sobre as encomendas de telas por parte do Museu Paulista, ver Caleb Faria Alves, 2000, cap. 3. O autor refere-se a encomendas feitas em 17 de maio de 1920 para José Wasth Rodrigues, Aurélio Zimmermam, Henrique Manzo, Niccolo Petrilli, Jonas de Barros, P. Gabbiati, Benedito Calixto e uma mulher, Maria Luiza Pompeu de Camargo. Sabemos que esta era paulista, uma expositora assídua dos Salões, premiada com menção honrosa e que se dedicava sobretudo à técnica da aquarela.

29 A tela de Auguste Bracet Primeiros Sons do Hino da Independência, que também foi adquirida no Centenário de 1922, celebra um evento histórico com uma solução de gênero. O pintor escolhe um tema - Dom Pedro I tocando ao piano o hino da Independência que se presta à ambientação doméstica, enfatizando o caráter privado e mesmo burguês de um episódio patriótico.

30 Tamar Garb, 1998, pp. 239-240.

31 Angione Costa, 1927, pp. 88

32 Esta é a tese defendida por Albert Boime em livro já citado. Bourdieu incorpora parcialmente essa idéia, ao definir a arte acadêmica como a "estética do acabado", ou seja, do fini.

33 Pierre Bourdieu, 1989, p. 270.

34 Idem, p. 271.

35 Idem, p. 273.

36 Com relação a esse período denominado III República, que compreende as décadas finais do século XIX, ver MAINARDI, Patricia Mainardi, 1994.

37 Alexandre Eulálio, 1992, p. 159.

38 A esse respeito ver Tamar Garb, 1998. A autora apresenta várias das metodologias propostas pelas feministas. Há um grupo que se dedica a estudar as pintoras esquecidas pela historiografia e mostrar sua genialidade, desse modo operando com o método tradicional da história da arte: busca pela individualização do artista. Um segundo grupo procura as condições sociais de produção da arte feita por mulheres e evita qualquer tipo de julgamento de suas obras. Parece-me que o último partido é o mais interessante para a sociologia da cultura, embora nem sempre seja fácil evitarmos juízos de valor acerca das obras.

39 Angione Costa, 1927, p. 85.

40 Georgina expôs seguidamente nos salões nacionais totalizando 16 participações. Foi a mulher com maior número de participações entre 1844 e 1922, seguida por Irene Ribeiro (12) e Nicolina Vaz (11). Foi também a mais premiada, obtendo todas as consagrações fornecidas pelo sistema, desde a simples menção honrosa até a grande medalha de ouro e, finalmente, a direção da Academia na década de 1950.

\section{BIBLIOGRAFIA}

ALVES, Caleb Faria. (2000), Benedito Calixto e a construção do imaginário republicano. São Paulo, tese de doutorado, FFLCH-USP.

BERNARDES, Maria Thereza Caiuby Crescenti. (1989), Mulheres de ontem: Rio de Janeiro, século XIX. São Paulo, T. A Queiroz.

BOIME, Albert. (s. d.), The academy \& French painting in the nineteenth century. New Haven/Londres, Yale University Press.

BOURDIEU, Pierre. (1989), "A institucionalização da anomia" e "Gênese história de uma estética pura", in bólico, Lisboa, Difel. O poder sim(1996), As regras da arte: gênese e estrutura do campo literário. São Paulo, Companhia das Letras.

(1999), A dominação masculina. Rio de Janeiro, Bertrand Brasil.

CALLEN, Anthea. (1997), "The body and difference: anatomy training at the Ecole des BeauxArts in Paris in the later nineteenth century". Art History, Londres, 20 (1), mar.

CAMPOFIORITO, Quirino. (1983), História da pintura brasileira no século XIX. Rio de Janeiro, Pinakoteke.

CARVAlHO, José Murilo de. (1990), "Repúblicamulher: de Marie a Marianne", in A Formação das almas: o imaginário da República no Brasil. São Paulo, Companhia das Letras. 
CAVALCANTI, Bernardete Dias. (1998), "O orientalismo no século XIX e a obra de Pedro Américo". Gávea (revista semestral do curso de especialização em História da Arte e Arquitetura no Brasil), Rio de Janeiro, PUC, 5.

CHADWICK, Whitney. (1996), Women, art, and society. Londres, Thames and Hudson (Coleção World of Art).

COLI, Jorge. (s. d.), A Batalha de Guararapes de Victor Meirelles e suas relações com a pintura internacional. Campinas, tese de livre-docência, Unicamp.

COSTA, Angyone (1927). A Inquietação das Abelhas. Rio de Janeiro, Pimenta de Mello \& Cia.

DEDIEGO, Estrella. (1987). La mujer y la pintura del XIX Español. Madrid, Ediciones Cátedra.

DENTON, Margaret Field. (1998), “A woman's place: the gendering of genres in post-revolutionary French painting". Art History, Londres, 21 (2), jun.

EISENMAN, Stephen F. (org.). (1994), Nineteenth cetury art: a critical bistory. Londres, Thames and Hudson.

ELEUTÉRIO, Maria de Lourdes. (1997), De esfinges e heroinas: a condição da mulher letrada na transição do fim do século. São Paulo, tese de doutorado, FFLCH-USP.

ELIAS, Norber. (1995), Mozart: a sociologia de um gênio. Rio de Janeiro, Jorge Zahar Editor.

EULÁLIO, Alexandre. (1992), "O século XIX: tradição e ruptura”, in Escritos, Campinas/São Paulo, Ed. Unicamp/Ed. Unesp.

FEHER, Catherine. (1994), "Women at the Académie Julian in Paris". The Burlington Magazine, Londres, CXXXVI (1100), nov.

GARB, Tamar. (1989), "L 'art féminin: the formation of a critical category in Late nineteebtg-Century France". Art History, Londres, 12 (1).
(1994), Sisters of the Brush: women's artistic culture in late nineteenthcentury Paris. New Haven/Londres, Yale University Press.

(1998), "Gênero e representação", in _ Modernidade e modernismo: a pintura francesa no século XIX. São Paulo, Cosac \& Naif.

(1999), "Men of genius, women of taste': the gendering of art education in late nineteenth-century Paris", in Overcoming all obstacles: the women of the Academie Julian, Nova York/Londres, Dahesh Museum \& Rutgers University Press.

GOMBRICH, E. H. (1986), Arte e ilusão: um estudo da psicologia da representação pictórica. São Paulo, Martins Fontes.

(1993), "Gesto ritualizado y expresion en el arte", in La imagen y el ojo: nuevos estudios sobre la psicologia de la representacion pictórica, Madrid, Alianza Editorial.

(1993), "La imagen visual: su lugar en la comunicacion", in La imagen y el ojo: nuevos estudios sobre la psicologia de la representacion pictórica, Madrid, Alianza Editorial.

GONZAGA-DUQUE ESTRADA, Luis. (1995 [1888]), A arte brasileira. Campinas, Mercado de Letras (introdução e notas de Tadeu Chiarelli).

GRAND dictionnaire universal du XIX siécle. (1872), Larrousse, Paris.

MAINARDI, Patricia. (1994), The end of the salon: art and state in the Early Third Republic. Nova York, Cambridge University Press.

MARQUES, Luis. (2001), Mestres da pintura no Brasil. São Paulo, Credicar.

MELLO E SOUZA, Antonio Candido de. (2000), Literatura e sociedade. São Paulo, Publifolha.

MICELI, Sergio. (1996), Imagens negociadas: retratos da elite brasileira (1920-1940). São Paulo, Companhia das Letras. 
MIGLIACCIO, Luciano. (2001), "Rodolfo Amoedo: o mestre, deveríamos acrescentar", in Luis Marques (org.), 30 mestres da pintura no Brasil, São Paulo, Credicard.

(2000), "O século XIX". Mostra do Redescobrimento: O Século XIX. São Paulo, Associação Brasil 500 Anos, Artes Visuais.

NAVES, Rodrigo. (1997), "Debret, e o neoclassicismo e a escravidão", in A forma dificil: ensaios sobre arte brasileira, São Paulo, Ática.

NOCHLIN, Linda. (1994), "The imaginary orient", in The politics of vision: essays on nineteenth-century art and society, Londres, Thames and Hudson.

PEVSNER, Nicokolaus.(s. d.), Les académies d'art. Gérard Monfort Ed., mimeo.

POLLOCK, Griselda. (1994), Vision \& difference: feminity, feminism and the bistories of art. Londres, Routledge.

(1998), Mary Cassatt: a painter of modern women. Londres, Thames and Hudson.

POMBO, Rocha. (1905), História do Brasil ilustrada. Rio de Janeiro, Saraiva, vol. VIII.

SAUER, Marina. (1990), L'entrée des femmes à l'École des Beaux-Arts, 1880-1923. Paris, ENSBA.
SMITH, Edwar-Lucie. (1989), Life class: the academic male nude, 1820-1920. Londres, GMP.

SCHORSKE, Carl. (1990), Viena fin-de-siècle: politica e cultura. São Paulo, Companhia das Letras.

TEIXEIRA LEITE, José Roberto. (1979), "A 'Belle Époque"”. Arte no Brasil. São Paulo, Abril Cultural, vol 2.

WEISBER, Gabriel \& BECKER, Jane. (2000), Overcoming all obstacles: the women of the Académie Julian. Nova York/Londres, The Dahesh Museum/Rutgers University Press.

WHITE, Harrison \& WHITE, Cynthia. (1993), Canvas and carrers: institucional change in the French painting world. Chicago/Londres, The University of Chicago Press.

WILLIAMS, Raymond. (1999), "A fração Blomburry". Plural (revista de pós-graduação em Sociologia), São Paulo, USP, 6.

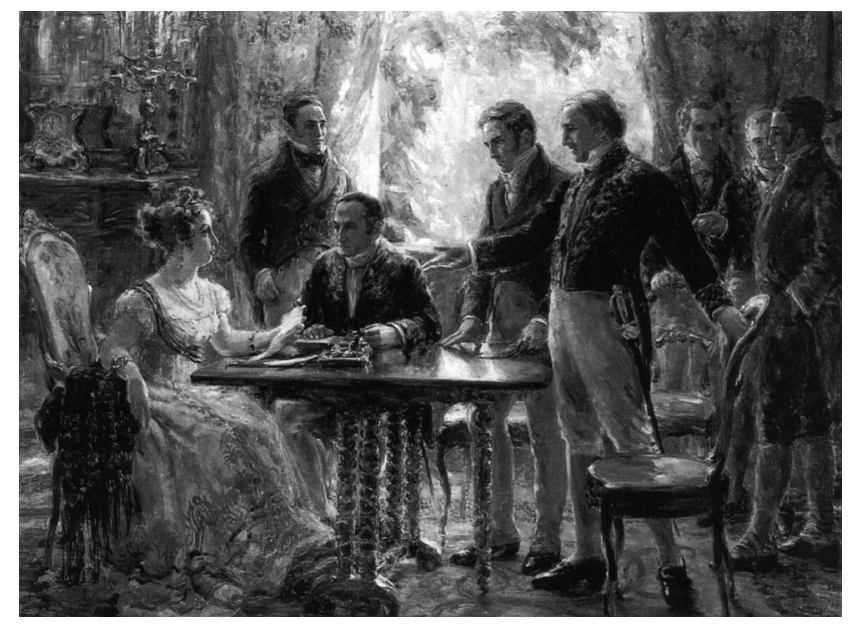

1. Georgina de Albuquerque

Sessão do Conselho de Estado, 1922

Museu Histórico Nacional. 


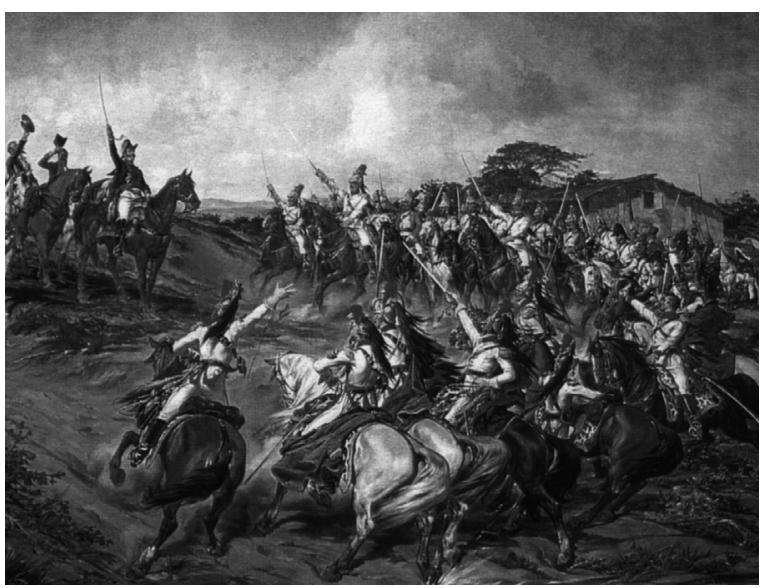

2. Pedro Américo de Figueiredo e Mello Independência ou Morte!, 1888

Museu Paulista

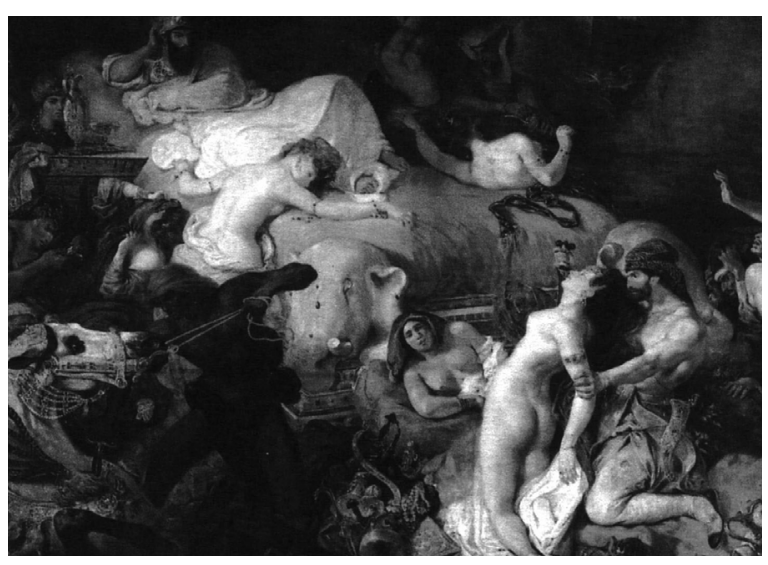

4. Eujène Delacroix

A Morte de Sardanapaulus, 1827

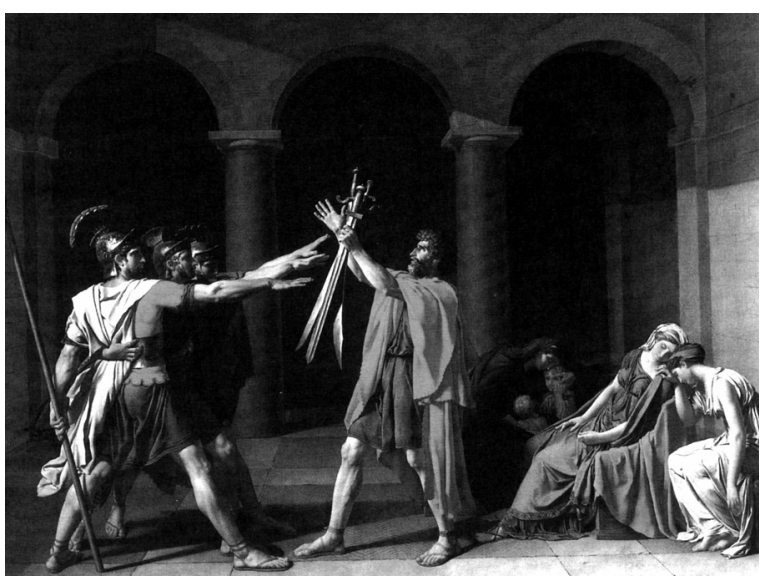

3. Jacques Louis David

O Julgamento dos Horácios, 1785

Paris, Louvre

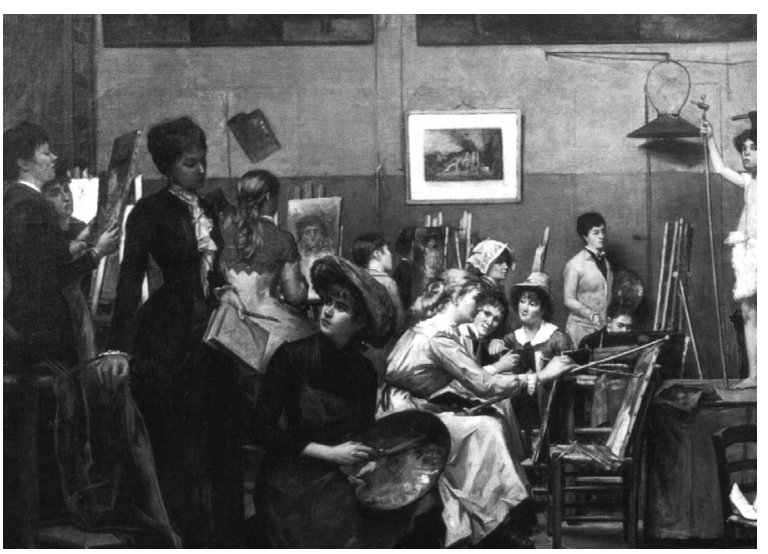

5. Marie Bashkirseff

In the Studio, 1881

Museum, Dnipropetroust 


\section{ENTRE CONVENÇÕES E DIS- CRETAS OUSADIAS: GEORGI- NA DE ALBUQUERQUE E A PINTURA HISTÓRICA FEMINI- NA NO BRASIL}

\section{Ana Paula Cavalcanti Simioni}

\section{Palavras-chave}

Pintura histórica; Mulher; Academia; Arte.

A partir da tela Sessão do Conselho de Estado, de Georgina de Albuquerque, pretendo discutir a relação entre as artistas mulheres e a Academia de Belas Artes no Brasil, recuperando o modo com que foram excluídas, ao longo do século XIX, das possibilidades de acessarem $\mathrm{O}$ mais alto grau de consagração dentro do sistema: a realização da pintura histórica. A primeira obra no gênero executada por uma artista nativa data justamente do ano símbolo do declínio da instituição: 1922. Segundo uma perspectiva que leva em consideração as prerrogativas do gênero, a artista realizou uma obra ousada. Porém, se os critérios utilizados são de ordem estilística, sua obra tende a ser vista como conservadora. Por isso pode ser percebida como uma "ousadia discreta", se interpretada à luz de balizas estéticas, institucionais, educacionais e, também, sexuais.

\section{BETWEEN CONVENTIONS AND DISCREET DARING: GEORGINA DE ALBUQUERQUE AND THE HISTORICAL FEMININE PAINTING IN BRAZIL}

Ana Paula Cavalcanti Simioni

\section{Keywords}

Historical Painting; Woman; Academy; Art

Based on Georgina de Albuquerque's painting "Session of the Council of State," I intend to discuss the relationship between women painters and the Brazilian Academy of Fine Arts, analysing how, during the 19th century, these women were excluded from the possibility of accessing the highest degrees of recognition within the academic system: historic painting. Coincidentally, the first historic painting by a Brazilian woman dates exactly from the year that marks the decline of the Academy: 1922. If it is analysed based on the genre's prerogatives, Georgina de Albuquerque's work can be considered daring. It is a historic painting and at the same time it is conservative, if its analysis is based on stylistic criteria. Therefore, this work may be interpreted as "discreetly daring" if considered from an aesthetic, institutional, educational or even sexual perspective.

\section{ENTRE CONVENTIONS ET DISCRÈTES AUDACES : GEORGINA DE ALBUQUERQUE ET LA PEIN- TURE HISTÓRIQUE FÉMININE AU BRÉSIL}

Ana Paula Cavalcanti Simioni

\section{Mots-clés}

Peinture historique; Femme; Académie; Art.

À partir du tableau "Séance du Conseil d'État", de Georgina de Albuquerque, je me propose de discuter le rapport entre les femmes peintres et l'Académie des BeauxArts du Brésil, en retraçant leur parcours et la façon dont elles ont été empêchées, tout au long du $\mathrm{XIX}^{\mathrm{e}}$ siècle, d'accéder au plus haut degré de consécration dans le système : la réalisation de la peinture historique. La première ouvre de ce genre, peinte par une artiste native, date justement de l'année qui symbolise le déclin de l'académisme : 1922. Dans une perspective prenant en compte les prérogatives du genre, cette artiste a réalisé une œuvre osée. Néanmoins, si les critères sont de nature stylistique, son ouvre sera plutôt considérée conservatrice. Ainsi, si l'on examine son art à la lumière des repères esthétiques, institutionnels, éducationnel, voire sexuels, il peut être perçu comme une "audace discrète". 